\title{
Comparative Analysis of Analog and Digital Controllers for Negative Output Superlift Luo Converter (NOSLC)
}

\author{
Chamundeeswari Vinayagam ${ }^{1}$, Seyezhai Ramalingam ${ }^{2}$ \\ ${ }^{1}$ Department of EEE, St. Joseph's College of Engineering, Chennai, India \\ ${ }^{2}$ Department of EEE, SSN College of Engineering, Chennai, India \\ Email: chamuvins@gmail.com,seyezhair@ssn.edu.in
}

Received 7 April 2016; accepted 5 May 2016; published 16 June 2016

Copyright (C) 2016 by authors and Scientific Research Publishing Inc.

This work is licensed under the Creative Commons Attribution International License (CC BY). http://creativecommons.org/licenses/by/4.0/

(c) (i) Open Access

\section{Abstract}

This paper focuses on the comparative study of analog and digital control techniques for Negative Output Superlift Luo converter (NOSLC). NOSLC is a high gain converter in which the positive source voltage is converted into a negative load voltage. Though the negative load voltage is produced effectively, there is lot of non-linearities that affects the voltage level. To overcome this, analog controllers like Proportional-integral (PI), fuzzy PI and a sliding mode controller (SMC) were proposed for NOSLC. However PI controller does not respond to changes in operating point, fuzzy PI is based on the systematic approach and proved to be a trial and error oriented method and SMC brings an oscillation in the duty cycle. Therefore, to overcome these drawbacks, a digital control technique using PIC microcontroller is proposed in this paper which provides high versatility and programmability approach. Simulation studies are carried out in MATLAB and the performances of these controllers have been investigated for the proposed DC-DC converter. A prototype of the NOSLC converter is built by employing digital control and the results are verified experimentally.

\section{Keywords}

Proportional-Integral, Fuzzy, Sliding Mode Control, Digital Controller

\section{Introduction}

The rapid development in DC-DC conversion finds applications in various industries. This has led to the production of DC voltage from various converters and here the significance is on the negative voltage. NOSLC is a type of DC-DC converter in which the output negative voltage increase is shown as a progressive rise. It also 
possesses a fast response with a low voltage overshoot and a minimum ripple.

To have a good regulation in the output voltage, various controllers were designed and implemented. This paper focuses on PI, fuzzy PI, sliding mode and digital controllers. These controllers provide a good response thereby bringing the output to a steady state value.

Initially, PI controller is designed and implemented for NOSLC. The values of $\mathrm{Kp}$ and $\mathrm{Ti}$ are tuned using Ziegler-Nichols tuning and applied in the transfer function of the controller and simulated using Matlab. Though the controller proves to be a better linear controller it may not respond well to changes in the operating point. To overcome this, a non-linear controller namely fuzzy PI controller is designed by fuzzyfying the Kp and Ti values with the expert knowledge. Here, it works only for systematic approach and prefers the trial and error method in the absence of expert understanding. So a robust method of control is implemented using SMC for uncertainties and other disturbances. However this control is also a time delayed one and brings oscillation in the output voltage with the duty cycle variations. Finally a digital control using peripheral interface controller is implemented which highly helps in reducing the usage of passive components and with an ease to integrate with digital systems. It also provides an inherent programmability approach.

The following sections will reveal the operation of NOSLC with its complete performance analysis of controllers. Section 2 deals with the modes of operation of NOSLC and Section 3 depicts the simulation results of NOSLC and Section 4 deals with the design of various controllers for NOSLC and Section 5 portrays the PI controller design and Section 6 deals with fuzzy PI controller. The SMC technique has been dealt in Section 7 and Section 8 portrays the digital control technique followed by conclusion in Section 9.

\section{Modes of Operation of NOSLC}

The NOSLC is a DC-DC converter which has a high gain, high efficiency and a low value of ripple. Here the NOSLC elementary circuit is considered which is operated with two modes as mosfet switch on and off.

Circuit diagram of NOSLC is shown in Figure 1. It comprises of supply voltage Vin, capacitor elements C1 and C2, inductor L1, MOSFET switch S, diodes D1 and D2 and resistive load R. The two modes of operation is as follows. During one period of the switch, C2 charges fast to a magnitude of Vin. The inductor current increases gradually with a value of Vin/L1 and during switch off, it decreases with a magnitude of (Vo - Vin)/L1. Here the output voltage is Vo. when the switch is closed, the input current flows through the inductor L1 and charges $\mathrm{C}$, and during the same time, the capacitor discharges through the load and thus the load voltage is produced. During mode-2, the switch is open and the inductor L1 and capacitor C2 discharges through the load which gives the boosted output Voltage. Using minimum number of elements, the circuit produces a boosted voltage and thus has its significance.

Based on the design equations, [1] the parameter of NOSLC has been shown in Table 1. It depicts the desired duty ratio and the output voltage increase for the corresponding input voltage in geometric progression. It has been computed for high switching frequency. It shows the input voltage, output voltage calculated. Thus the gain increase [2] is also shown for NOSLC.

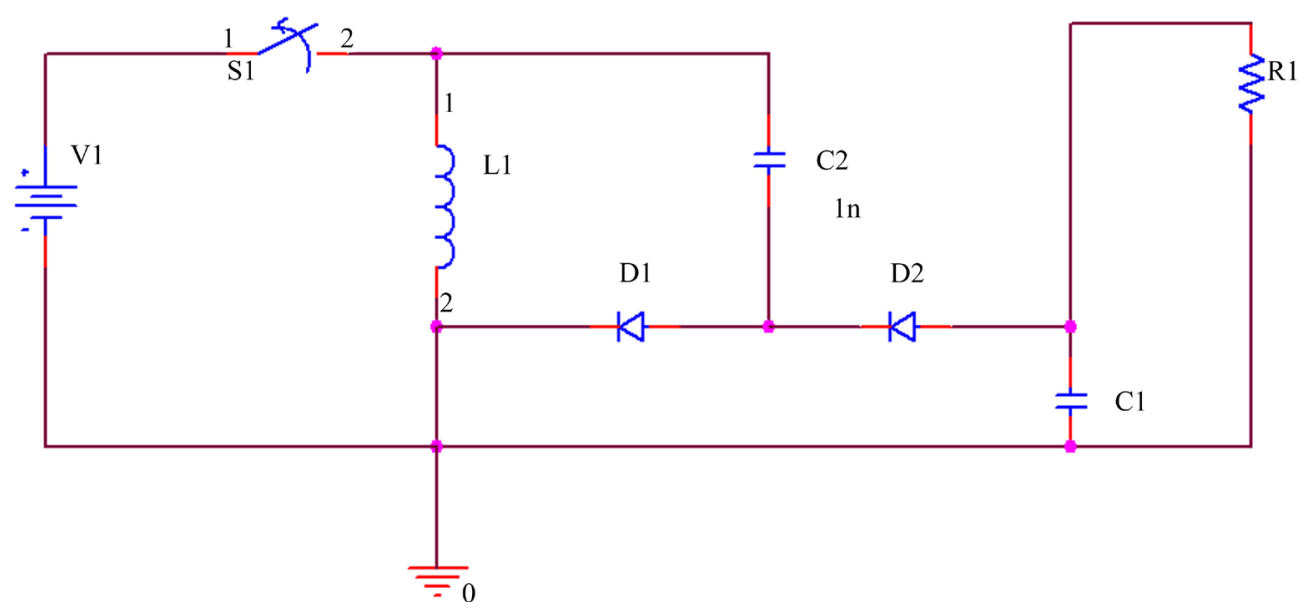

Figure 1. NOSLC-circuit diagram. 


\section{Simulation Results}

The simulation of NOSLC is carried out using Matlab. The output voltage rise to $-34 \mathrm{~V}$ for an input of $12 \mathrm{~V}$ is shown in Figures 2-4 depicts the switching pulse of 67\% duty ratio. Figure 5 and Figure 6 depicts the current through the inductor as $25 \mathrm{~mA}$ and voltage across the capacitor $\mathrm{C} 1$ as $11 \mathrm{~V}$. Figure 7 shows the output current of NOSLC as $-0.65 \mathrm{~A}$.

\section{Design of Controllers for NOSLC}

To provide a regulation in the output voltage, controllers have to be designed and implemented for NOSLC. In

Table 1. Parameters of NOSLC.

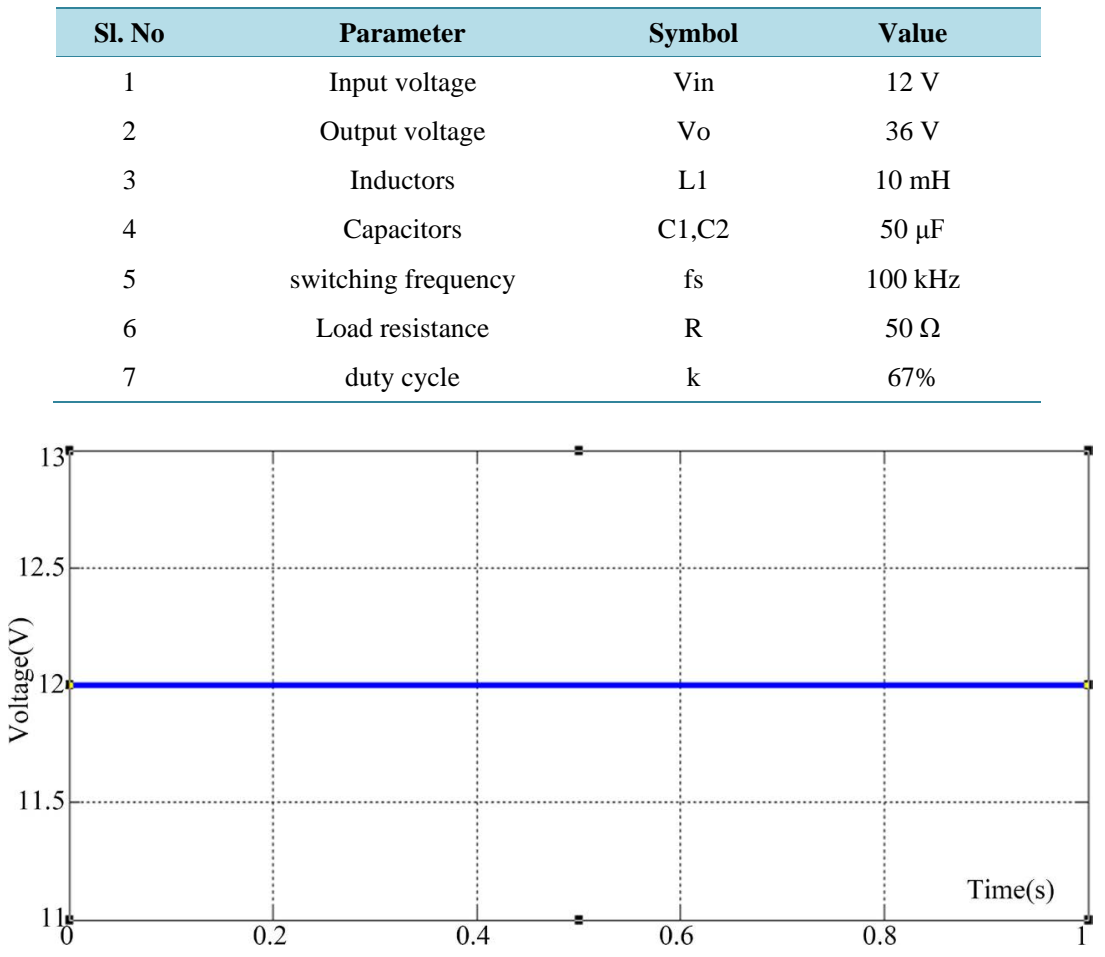

Figure 2. Input voltage of $12 \mathrm{~V}$.

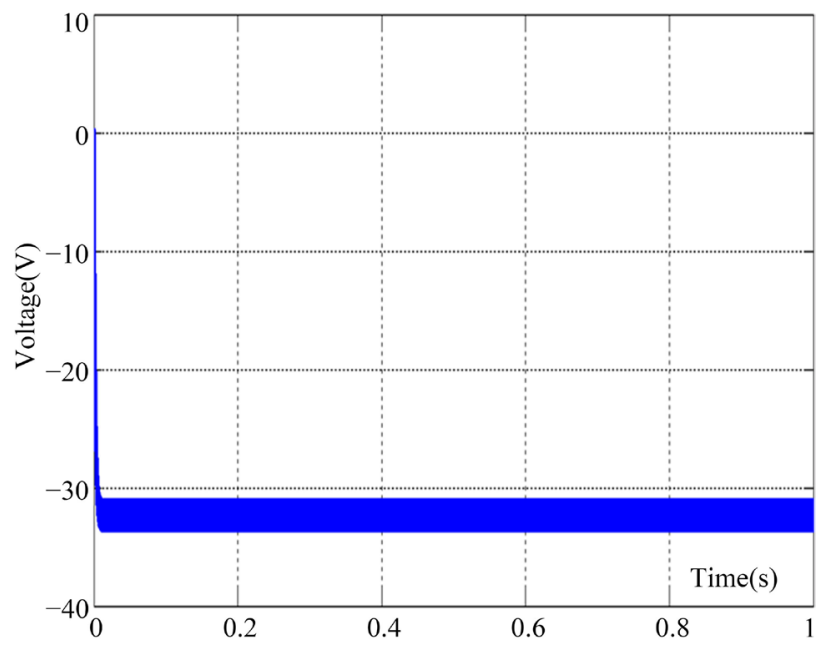

Figure 3. Output voltage of NOSLC $-34 \mathrm{~V}$. 


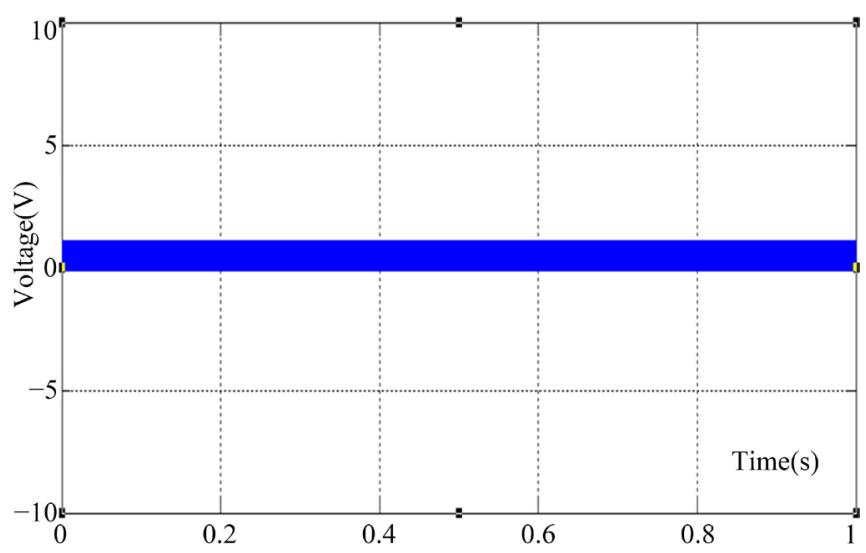

Figure 4. Switching pulse of NOSLC- 67\% Duty ratio.

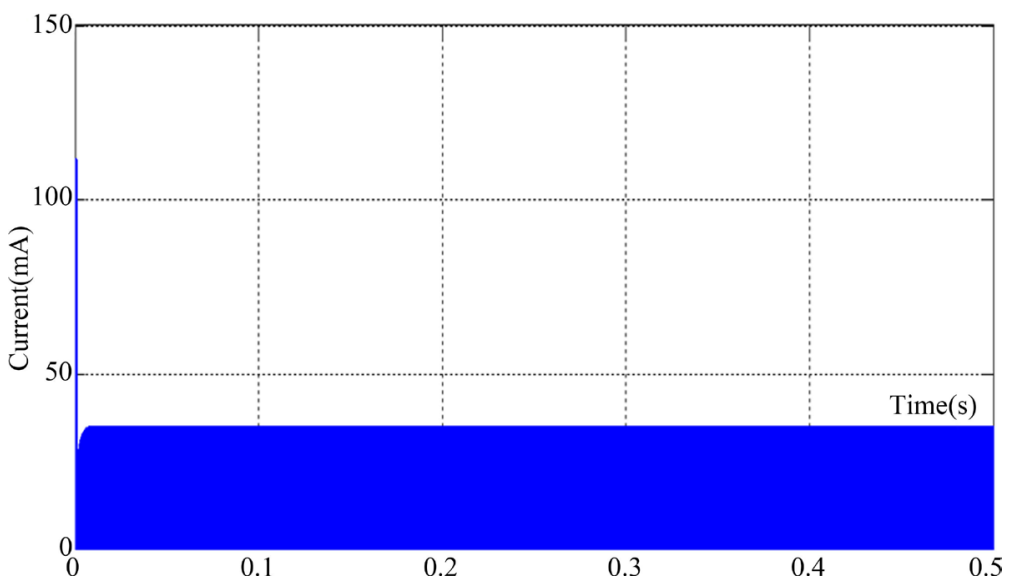

Figure 5. Current through the inductor L1.

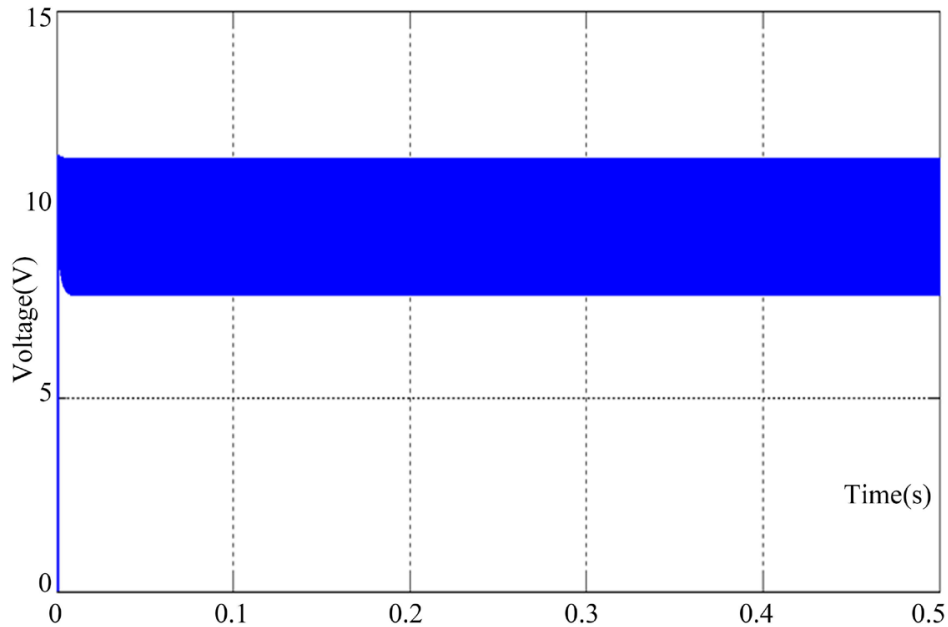

Figure 6. Voltage across the capacitor C1.

this regard, various controllers have been taken for study and designed and implemented and its performance comparison is also carried out. The following sections will reveal the merits of each and every controller taken for NOSLC. It also deals with the various analog and digital controllers of NOSLC. The linear analog controller namely PI controller, the non-linear fuzzy PI controller, is designed and implemented. Further SMC control and digital control is implemented for NOSLC to have an enhanced regulation. 


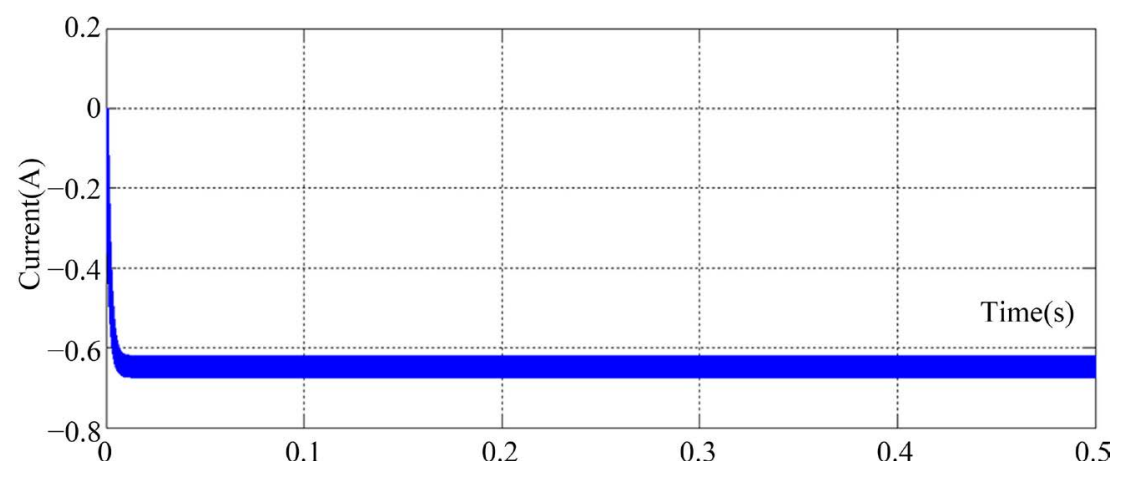

Figure 7. Output current of NOSLC.

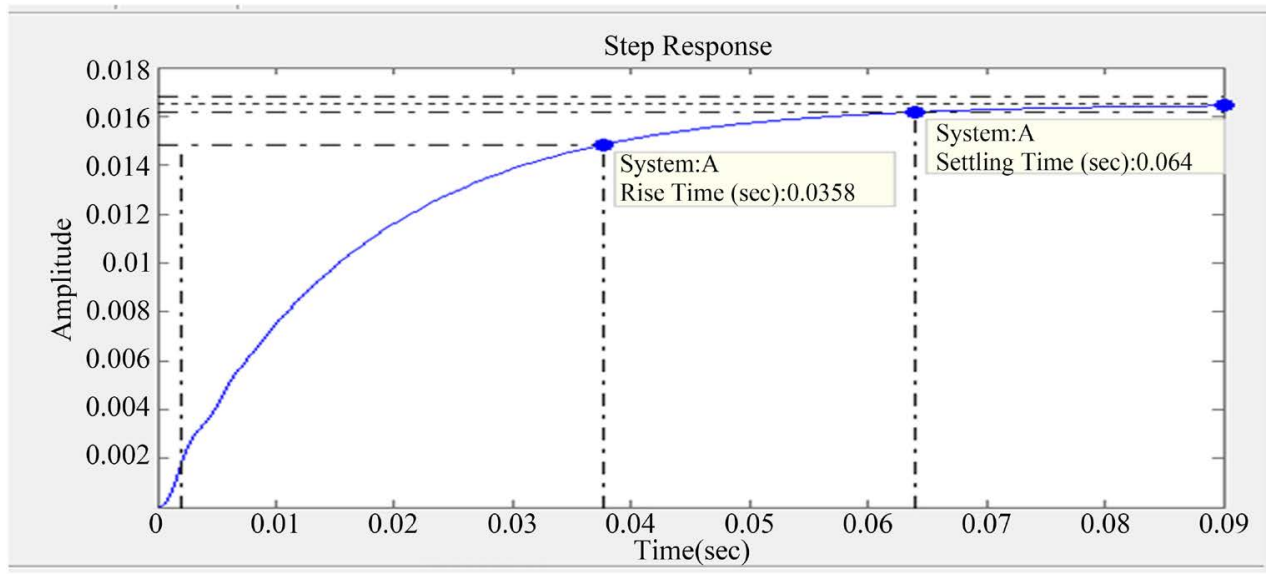

Figure 8. Step response of NOSLC.

\section{PI Control for NOSLC}

This section deals with design of PI controller. These types of controllers modify the error signal and produce a proper output [3]. The converter transfer function is calculated for the PI controller and the step response is plotted. From the response curve, Kp and Ti values are estimated using Ziegler-Nichols tuning [4]. These values of $\mathrm{Kp}$ and $\mathrm{Ti}$ are then used for predicting the transfer function of the controller and then simulated and the respective output voltage is obtained [5]-[7].

Figure 8 shows the step response plotted from the transfer function obtained for the converter. The values of the settling time, rise time, delay time are represented in the step response curve and from that the transfer function of the controller is found and applied in closed loop control as shown in Figure 9. The switching pulse generated is shown in Figure 10. Figure 11 depicts the waveforms of NOSLC showing the input and output voltage. It shows that for an input of $12 \mathrm{~V}$, the PI controller regulates the output to $-34 \mathrm{~V}$.

\section{Fuzzy PI Controller for NOSLC}

The PI controller proves to be a good linear controller but may not respond well to non-linear conditions. Hence fuzzyfying the values of $\mathrm{Kp}$ and $\mathrm{Ti}[8]$ using expert understanding system make it act as a very good non-linear controller thereby overcoming drawbacks of PI controller.

Figure 12 shows the closed loop control of NOSLC using fuzzy PI controller. The error and change in error is given as an input to the fuzzy controller and the $\mathrm{Kp}$ and $\mathrm{Ti}$ values are fuzzified to get the output response for NOSLC [9]. Figure 13 shows the output waveform of NOSLC using fuzzy PI controller, which also depicts the steady state value. It shows for an input voltage of $12 \mathrm{~V}$, the output voltage get boosted to $-34 \mathrm{~V}$ and the voltage across the capacitor C1 is shown as $11 \mathrm{~V}$. Table 2 and Table 3 depict the fuzzy rules of Kp and Ti. The rule table denotes seven different possible values for the error as negative big, medium and small followed by zero. It also shows the values in terms of positive big, medium and big. With the values of error and change in error, the 
duty ratio is generated for the switching pulse to get the desired output.

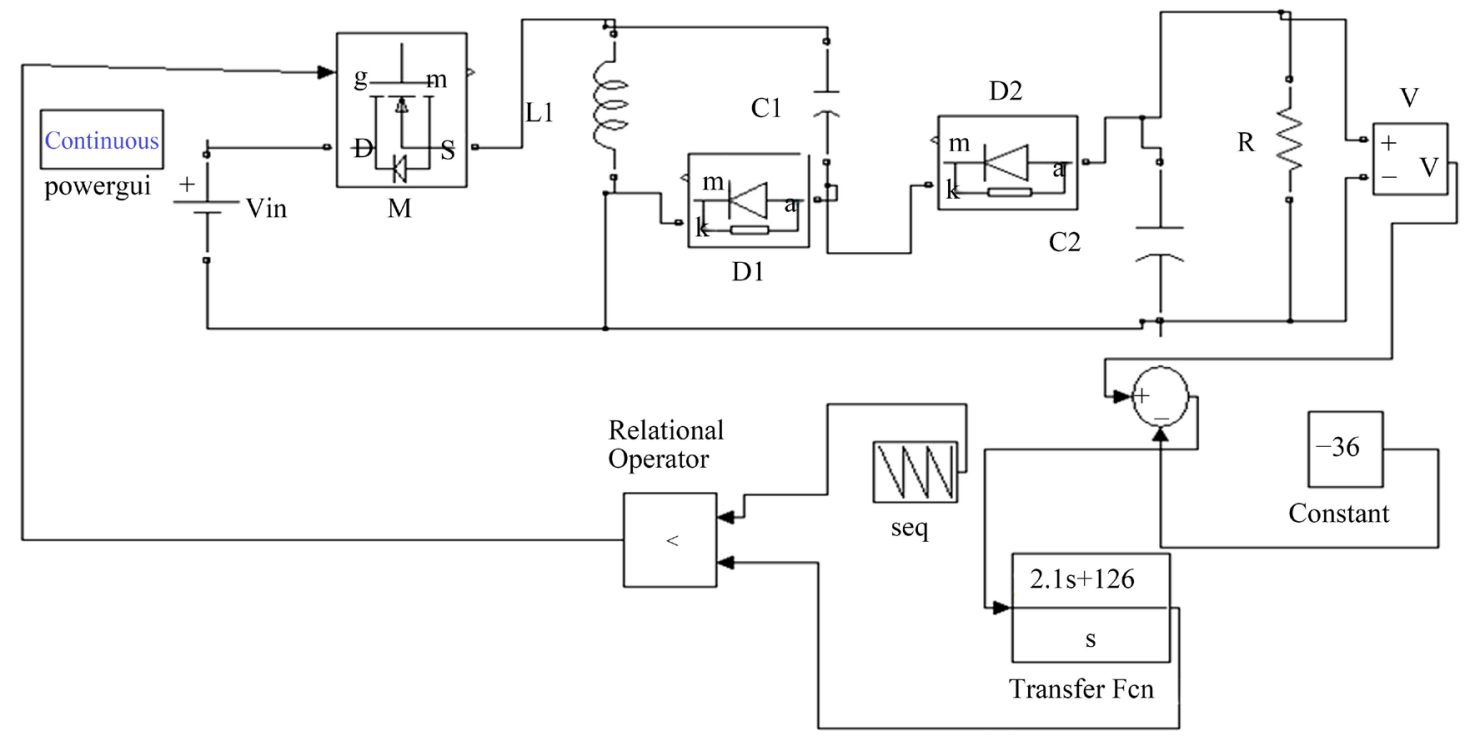

Figure 9. Closed loop control of NOSLC using PI controller.

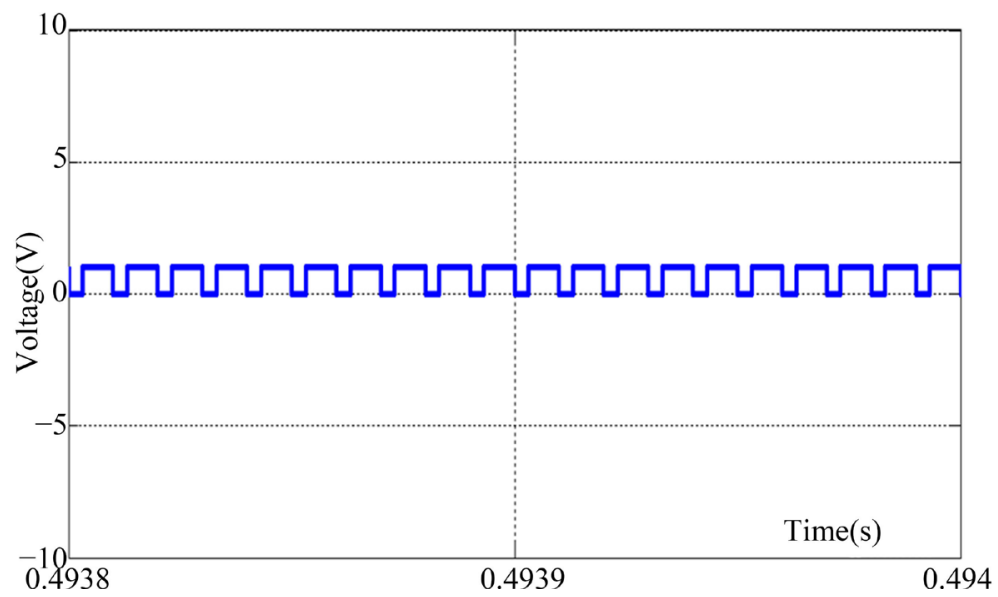

Figure 10. Switching pulse.
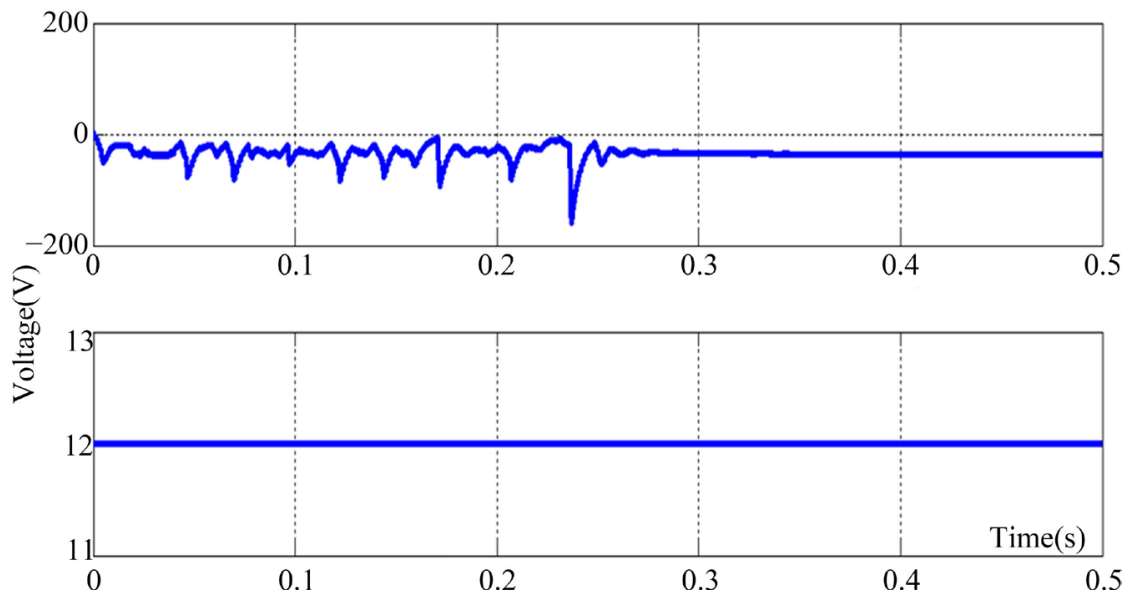

Figure 11. Input and output waveforms of NOSLC using PI controller. 


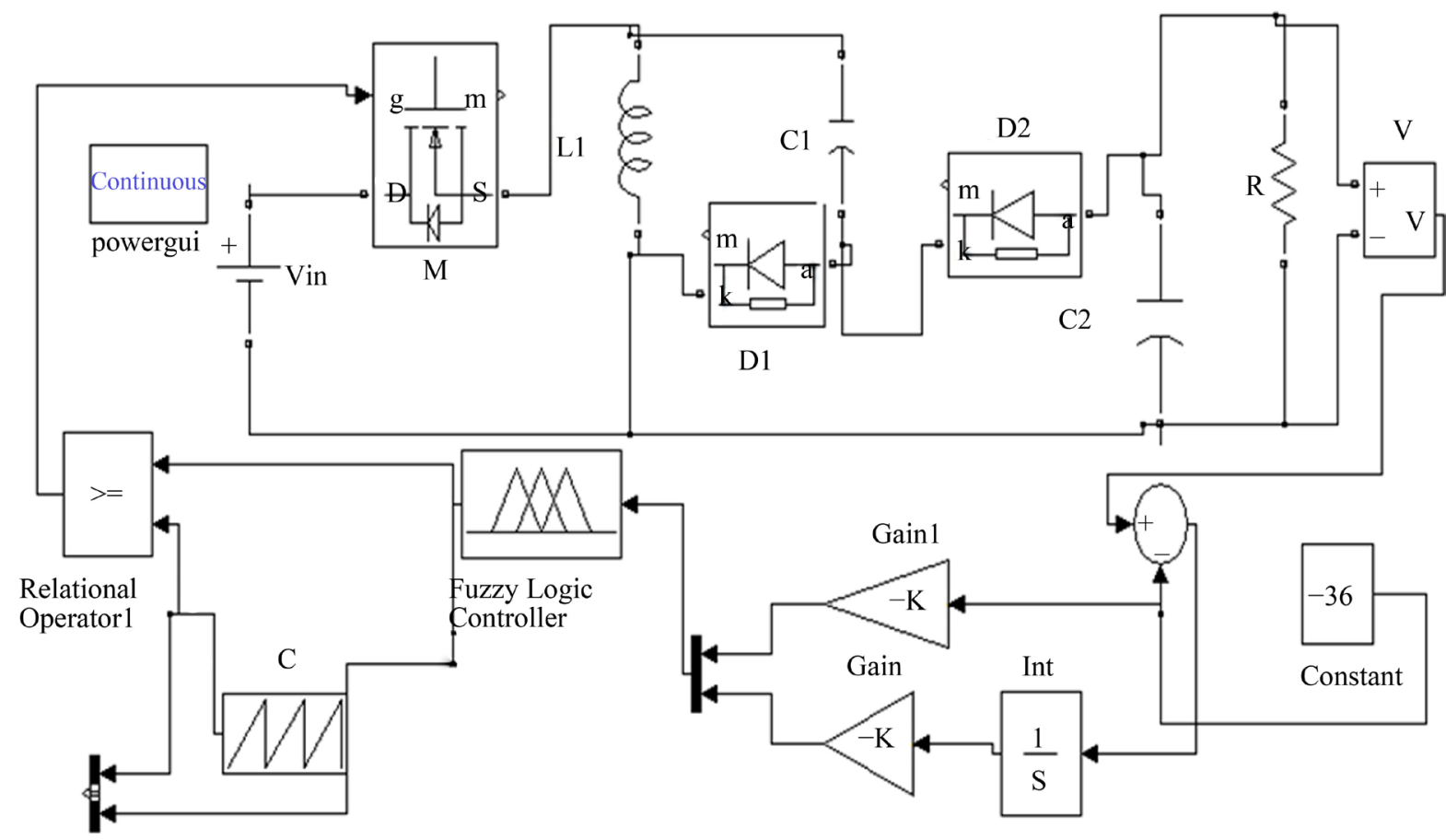

Figure 12. Closed loop control of NOSLC using fuzzy PI controller.
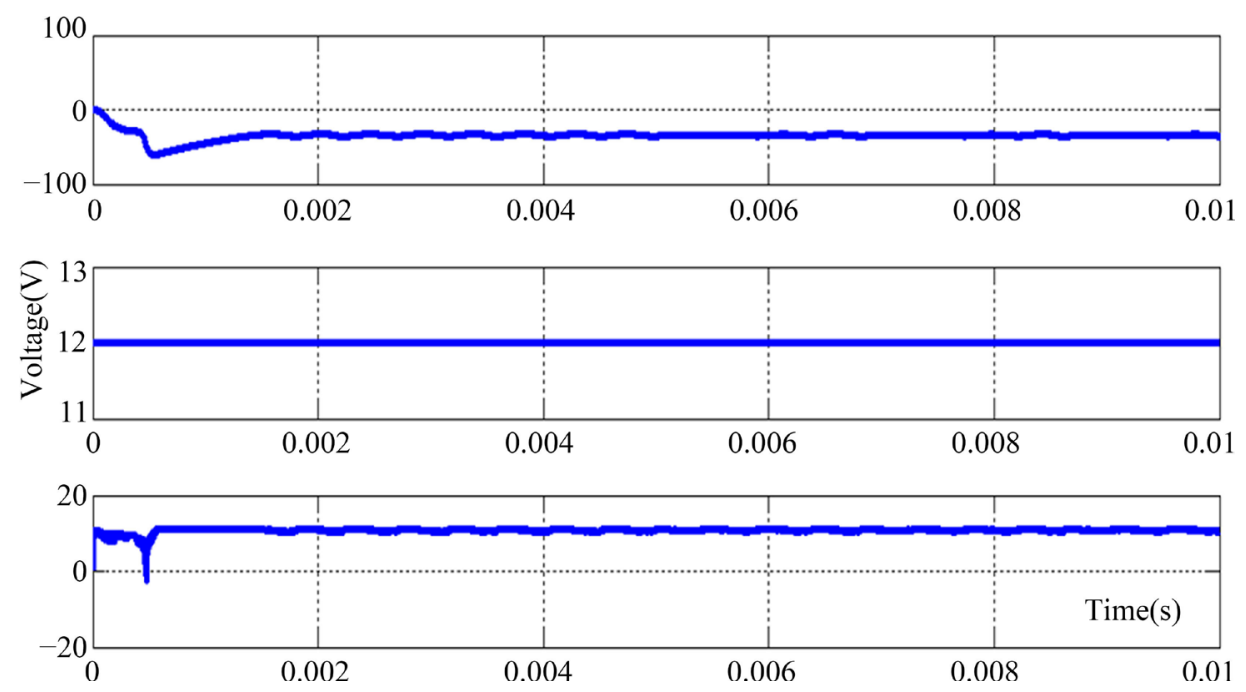

Figure 13. Output voltage, input voltage and capacitor C1 voltage of NOSLC using fuzzy PI controller.

Table 2. Fuzzy rules for $K_{p}$.

\begin{tabular}{cccccccc}
\hline e/de & NB & NM & NS & ZR & PS & PM & PB \\
NB & NB & NB & NB & NB & NS & ZR & PS \\
NM & NB & NB & NB & NM & NS & ZR & PS \\
NS & NB & NB & NM & NS & ZR & PS & PM \\
ZR & NB & NM & NS & ZR & PS & PM & PB \\
PS & NM & NS & ZR & PS & PM & PB & PB \\
PM & NS & ZR & PS & PM & PB & PB & PB \\
PB & ZR & PS & PM & PB & PB & PB & PB \\
\hline
\end{tabular}


Table 3. Fuzzy rules for Ti.

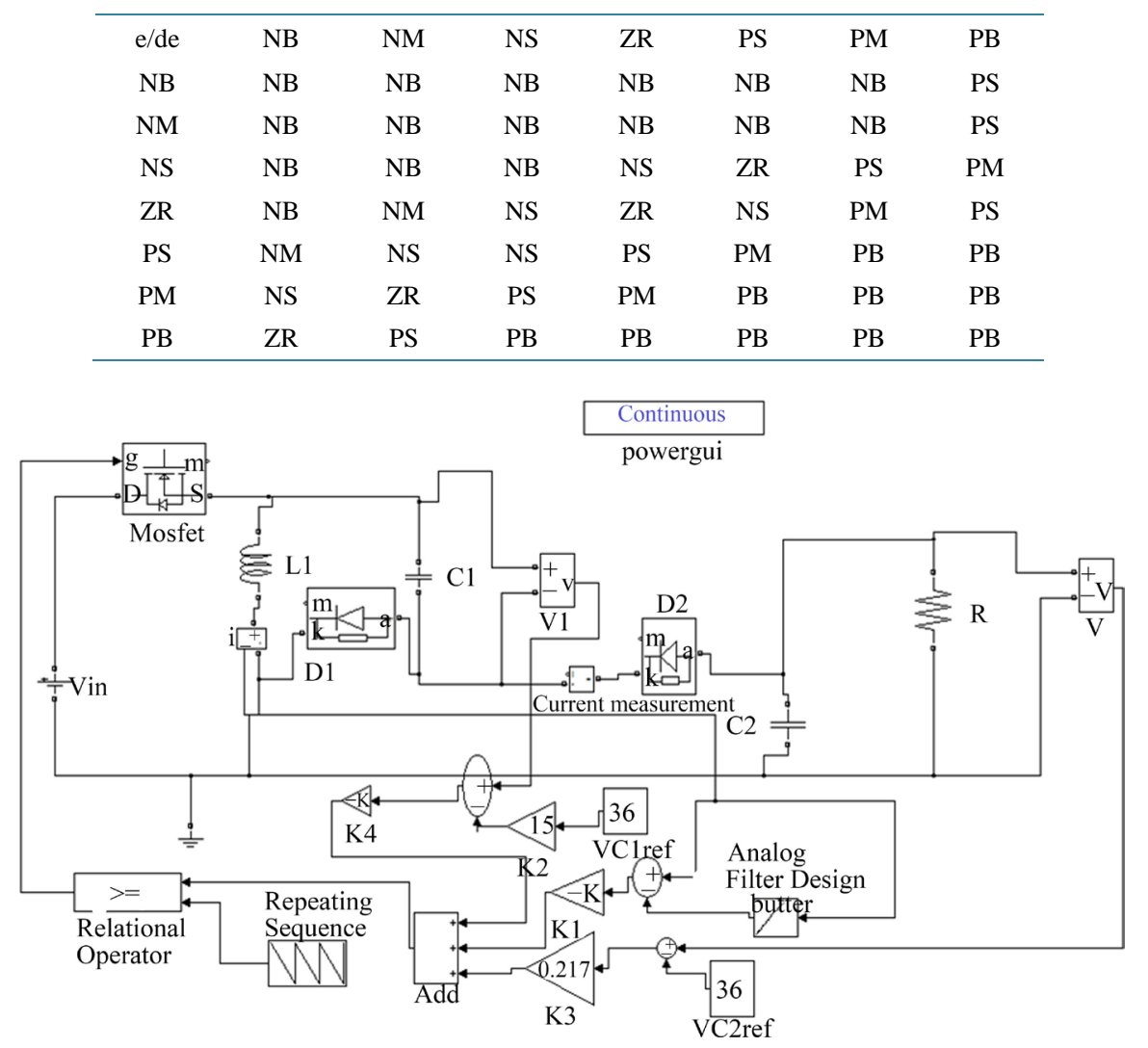

Figure 14. Sliding mode control of NOSLC.

\section{Sliding Mode Controller for NOSLC}

The PI controller and fuzzy PI controller has been explained. Though fuzzy PI controller proves to be a non-linear controller, it is predicted only by the expert knowledge which proves to be a trial and error oriented. To overcome this, sliding mode controller [10] is implemented which works with the concept of sliding coefficient selection [11].

The sliding mode control of NOSLC [12] is depicted in Figure 14. In this control, the inductor current, capacitor voltages are measured and compared with the reference variables of the respective current and voltages. The error is multiplied with its gain parameters and the summation of the outputs is obtained. This is again compared with the relational operator to generate a switching pulse with a proper duty ratio. Figure 15 depicts the output voltage of $-36 \mathrm{~V}$ for an input of $12 \mathrm{~V}$. It also shows the voltage across the capacitor $\mathrm{C}_{1}$ as $17 \mathrm{~V}$.

The switch pulse produced with a duty ratio of $67 \%$ is shown in Figure 16. The adapted value of duty ratio is selected to be 0.67 for an enhanced output voltage.

The relay is energized based on the summer output. Thus the relay output is considered as input to the switch and a closed loop will be achieved. Based on the variation parameter of load, input voltage, and change in component values the gain parameter is chosen and converter in closed loop control is executed. Various SMC techniques have been discussed in [13]-[15]. The sliding surface 'S' in SMC which decides the pulse of the converter is dependent on the following parameters.

$$
S=K_{1} e_{1}+K_{2} e_{2}+K_{3} e_{3}
$$

where

$$
\begin{aligned}
& e_{1}=V c_{2}-V c_{2 r e f} \\
& e_{2}=i L_{1}-i L_{1 r e f}
\end{aligned}
$$




$$
e_{3}=V c_{1}-V c_{1 r e f}
$$

$V c_{1}, V c_{2}$ and $i L_{1}$ is the voltage across the capacitor C1, C2 and current through the inductor L1 [13] [14] [19] [20] and it is followed by its reference values.

Table 4 depicts the significance of all the controllers namely PI, fuzzy PI and SMC with its rise time, settling time and peak overshoot values. It shows that the fuzzy PI and sliding mode controller reaches the steady state sooner than the PI controller. Though the fuzzy PI seems to have a better response, it is completely dependent on the expert understanding and trial and error methods. The settling time of the response in SMC also proves to be better with the sliding point selection but the oscillation in the duty cycle seems to be maximum and it is a complex structure oriented technique. Hence improved flexible and systematic approach with the reduced passive component usage is obtained only by digital control which is explained in the following section.

\section{Digital Implementation for NOSLC}

This section deals with the control of NOSLC using PIC 16F877A microcontroller. The closed loop control is depicted in Figure 17 and the comparison of various controllers is also shown [16]. It shows that the output voltage across the load is measured for the given input. Now if the load variation is sensed, the change in output voltage is brought to a stable value with the control of duty ratio of the switching pulse of the converter by PIC 16F877A microcontroller. Various techniques have been reported in [17] [18].
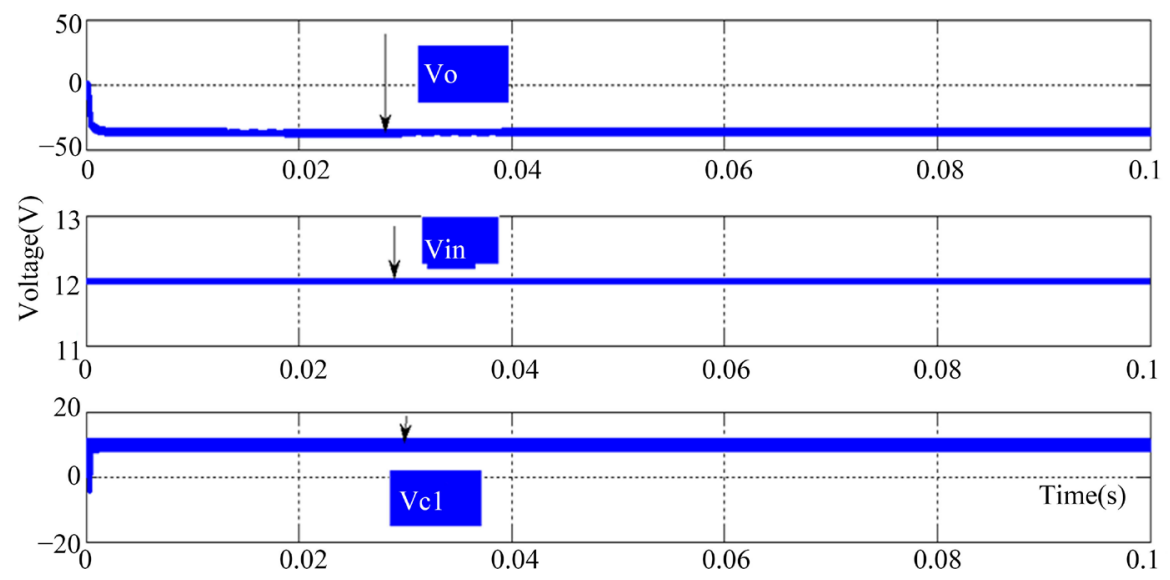

Figure 15. Output waveform of NOSLC using SMC controller.

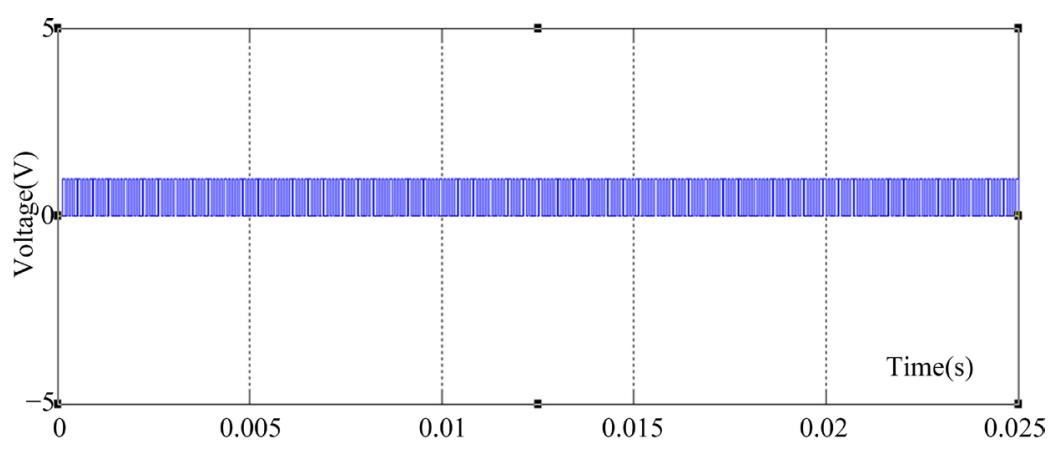

Figure 16. Gate pulse of the switch of NOSLC.

Table 4. Performance parameters of various controllers.

\begin{tabular}{cccc}
\hline Controller & Rise time $\mathrm{t}_{\mathrm{r}(\mathrm{s})}$ & Settling time $\mathrm{t}_{\mathrm{s}(\mathrm{s})}$ & Peak overshoot $(\% \mathrm{Mp})$ \\
\hline PI & 0.2 & 0.1 & 0.8 \\
Fuzzy PI & 0.002 & 0.04 & 0.005 \\
Sliding mode controller & 0.080 & 0.088 & 0.097 \\
\hline
\end{tabular}




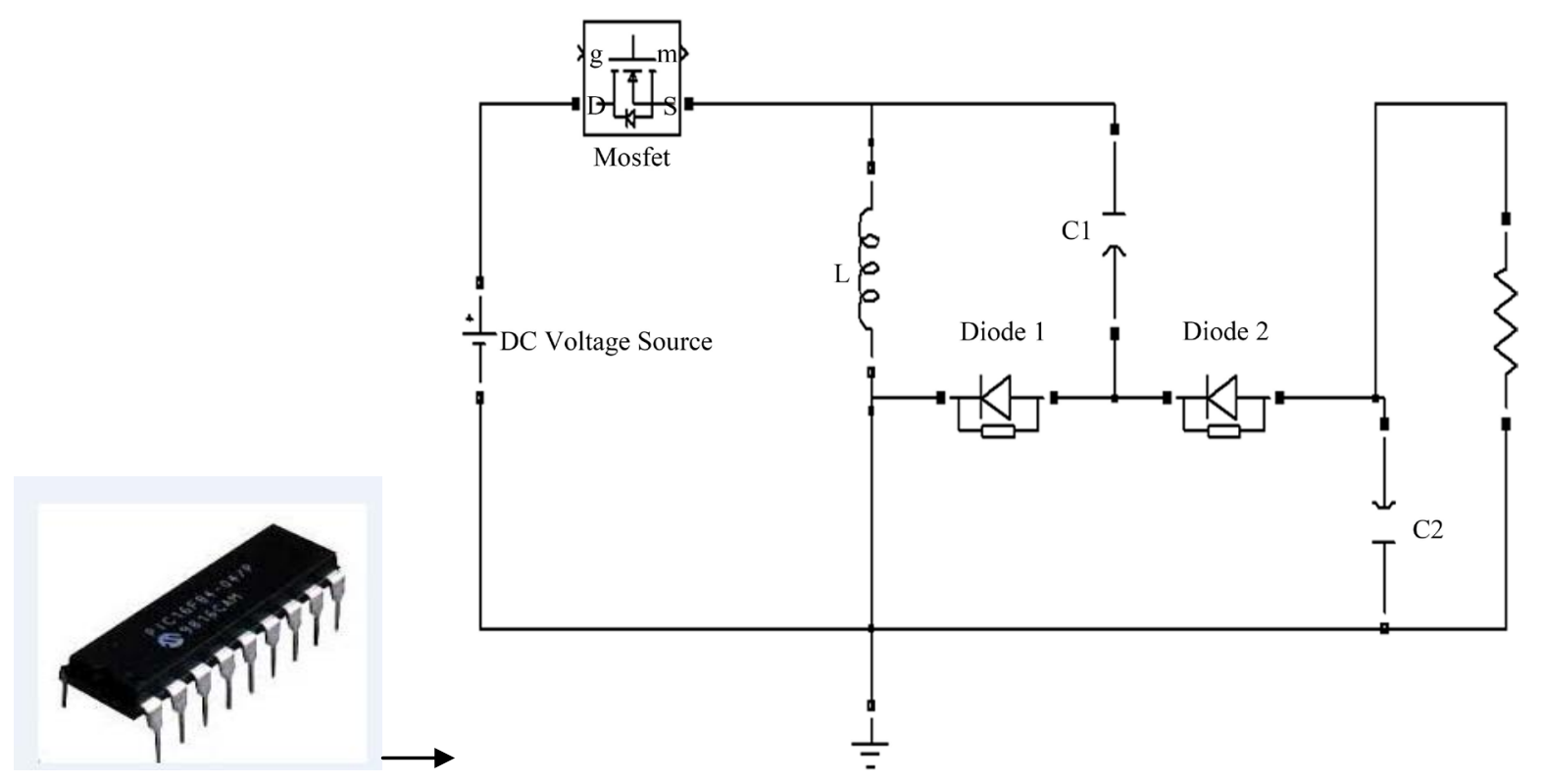

Figure 17. Digital control of NOSLC using PIC microcontroller.

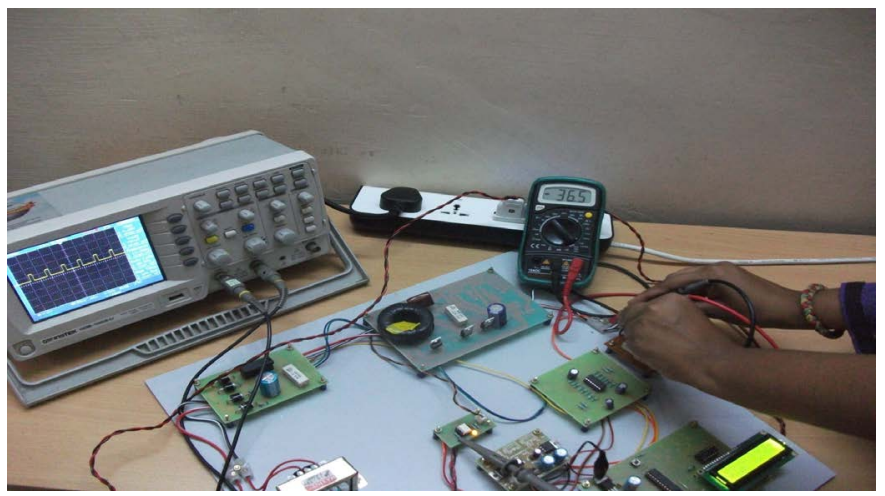

Figure 18. Prototype developed and output voltage measured as $-36.5 \mathrm{~V}$.

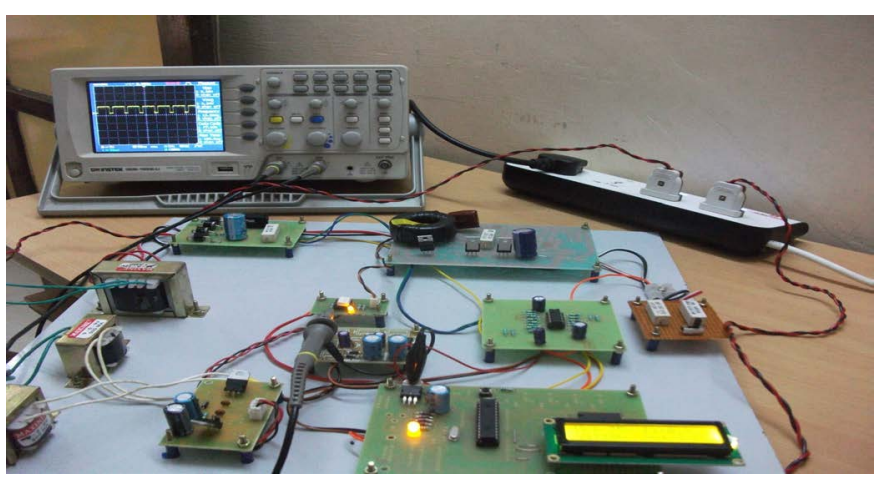

Figure 19. Pulse generated for $70 \%$ duty ratio for load of $300 \Omega$.

The control algorithm is implemented in PIC 16F877A microcontroller. The PWM signal with a duty ratio of $70 \%$ is generated for the initial load conditions by the PIC. Again when the load change is sensed, it generates a duty ratio of $20 \%$ and thus stabilizes the output which is shown in the experimental results.

Thus the digital technique with a good versatility approach has been clearly explained in the above section [19]. Hardware results of digital control are depicted in the Figures 18-20. Figure 18 shows the output voltage 


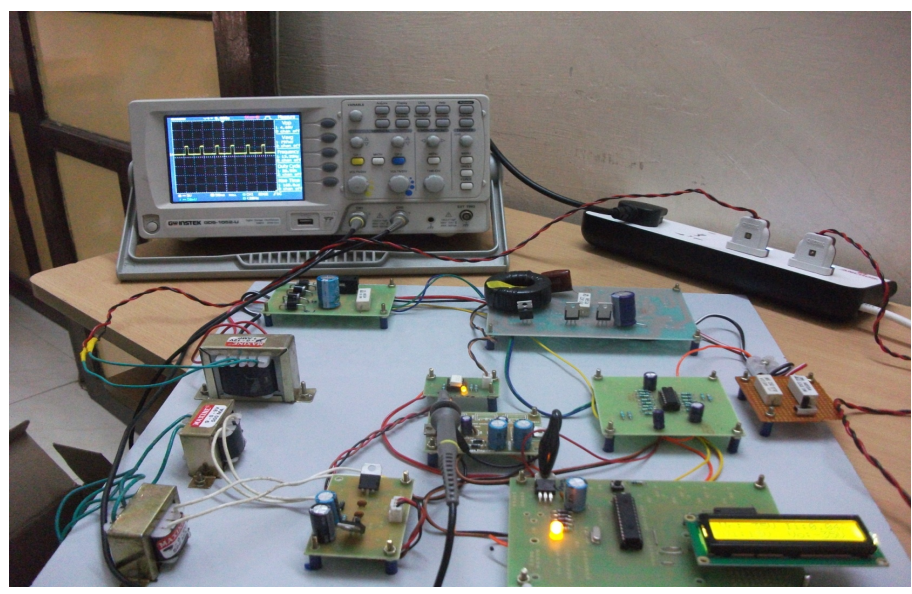

Figure 20. Pulse generated for $20 \%$ duty ratio for load of $2 \mathrm{k} \Omega$.

of $-36.5 \mathrm{~V}$ for an load of $300 \Omega$ and the generated duty ratio for that ohmic value is shown to be $70 \%$ (Figure 19). When the load changes to $2 \mathrm{~K} \Omega$, the corresponding duty ratio is changed to $20 \%$ as shown in Figure 20 and the stable voltage is maintained to $-35.9 \mathrm{~V}$. The features of various techniques are also reported [20].

\section{Conclusion}

Various controllers for NOSLC have been investigated in this paper. The PI controller makes the response of NOSLC to reach its steady state value after a long interval of time and hence proved to be a slow response controller. To compensate for non-linearities, and to reduce the settling time, fuzzy PI controller is implemented whose dynamic response is better compared to PI controller. SMC technique is implemented as fuzzy control is based on trial and error approach but, it is observed that SMC brings an oscillation in the duty cycle. Therefore, a digital controller is implemented and the performance of the converter is improved as it provided a better load regulation compared to the analog controllers, Therefore, digital control seems to be a better control technique for the negative output super lift Luo converter.

\section{References}

[1] Luo, F.L. and Ye, H. (2003) Negative Output Super-Lift Converters. IEEE Transactions on Power Electronics, 18, 1113-1121. http://dx.doi.org/10.1109/TPEL.2003.816185

[2] Jiao, Y, Luo, F.L. and Zhu, M. (2011) Voltage-Lift Type Switched-Inductor Cells for Enhancing DC-DC Boost Ability: Principles and Integration in Luo Converter. IET Power Electronics, 4, 131-142.

[3] Ramash Kumar, K. and Jeevananthan, S. (2010) PI Control for Positive Output Elementary Super Lift Luo Converter. World Academy of Science Engineering and Technology, 63, 732-737.

[4] Guo, L.P., Hung. J.Y. and Nelms, R.M. (2006) Digital Implementation of Sliding Mode Fuzzy Controllers for Boost Converters. 21st Annual IEEE Applied Power Electronics Conference and Exposition, Dallas, TX, 19-23 March 2006, 1424-1429.

[5] Arulselvi, U.G. and Chidambaram, M. (2004) Design of PID Controller for Boost Converter with RHS Zero. The 4th International Power Electronics and Motion Control Conference, Xi'an, 14-16 August 2004, Vol. 2, 532-537.

[6] Dhanasekar, N. and Kayalvizhi, R. (2012) Performance Evaluation of PI Control for Negative Output Triple Lift Luo Converter. IJEAT, 2, 55-57.

[7] He, M.Z. and Xu, J.P. (2007) Nonlinear PID in Digital Controlled Buck Converters. 22nd Annual IEEE Applied Power Electronics Conference and Exposition, Anaheim, CA, 25 February-1 March 2007, 1461-1465.

[8] Hsu, C.F., Chung, I.F., Lin, C.M. and Hsu, C.Y. (2009) Self Regulating Fuzzy Control for Forward DC-DC Converters Using an 8-bit Microcontroller. IET Power Electronics, 2, 1-13. http://dx.doi.org/10.1049/iet-pel:20070179

[9] Tang, K.S. and Kim, F.M. (2001) Optimal Fuzzy PID Controller. IEEE Transactions on Industrial Electronics, 48, 757-765.

[10] Ramash Kumar, K. and Jeevanathan, S. (2010) Design of Sliding Mode Control for Negative Output Elementary Superlift Luo Converter Operated in Continuous Conduction Mode. IEEE International Conference on Communication 
Control and Computing Technologies, Ramanathapuram, 7-9 October 2010, 138-148.

[11] Mahdavi, J., Emadi, A. and Toliyat, H.A. (1997) Application of State Space Averaging Method to Sliding mode Control of PWM DC DC Converters. Conference Record of the 1997 IEEE Industry Applications Conference, New Orleans, 5-9 October 1997, 820-827.

[12] Ramash Kumar, K. and Jeevananthan, S. (2009) Hysteresis Modulation Based Sliding Mode Control for Positive Output Elementary Super Lift Luo Converter. World Academy of Science, Engineering and Technology. International Journal of Electrical, Computer, Energetic, Electronic and Communication Engineering, 3, 895-902.

[13] Gupta, P. and Patra, A. (2003) Hybrid Sliding Mode Control of DC-DC Converters Circuits. TENCON, Conference on Convergent Technologies for the Asia-Pacific Region, 1, 259-263.

[14] Matas, J., deVicuna, L.G., Lopez, O., Lopez, M. and Castilla, M. (2000) Discrete Sliding Mode Control of a Boost Converter for Output Voltage Tracking. 8th International Conference on Power Electronics and Variable Speed Drives, London, 18-19 September 2000, 351-354.

[15] Ciccarelli, F. and Lauria, D. (2010) Sliding Mode Control of Bidirectional DC-DC Converter for Super Capacitor Energy Storage Applications. Power Electronics Electrical Drives Automation and Motion, SPEEDAM, Pisa, 14-16 June 2010, 1119-1122.

[16] Nasir, A.N.K., Raja Ismail, R.M.T. and Ahamed, M.A. (2010) Performance Comparison between Sliding Mode Control (SMC) and PD-PID Controllers for a Non-Linear Inverted Pendulum System. World Academy of Science, Engineering and Technology, 71, 400-405.

[17] He, Y. and Luo, F.L. (2010) Design and Analysis of Adaptive Sliding Mode-Like Controller for DC-DC Converters. IEE Proceedings of Electric Power Applications, 153, 401-410.

[18] Pavlovsky, M., Tsuruta, Y. and Kawamura, A. (2010) Recent Improvements of Efficiency and Power Density of DC-DC Converters for Automotive Applications. International Power Electronics Conference (IPEC), Sapporo, 21-24 June 2010, 1866-1873.

[19] Amjadi, Z. and Williamson, S.S. (2010) Efficiency Modeling and Comparison of Switched Capacitor, Luo and Interleaved Switched Capacitor Converters for Electric Vehicle Energy Systems. 36th Annual Conference on IEEE Industrial Electronics Society, Glendale, AZ, 7-10 November 2010, 1811-1817.

[20] Brea, E.A.J., Ortiz-Rivera, E.I., Salazar-Llinas, A. and Gonzalez-Llorente, J. (2010) Simple Photovoltaic Solar Cell Dynamic Sliding Mode Controlled Maximum Power Point Tracker for Battery Charging Applications. 25th Annual IEEE Applied Power Electronics Conference and Exposition (APEC), Palm Springs, CA, 21-25 February 2010, 666671.

\section{Submit or recommend next manuscript to SCIRP and we will provide best service for you:}

Accepting pre-submission inquiries through Email, Facebook, Linkedin, Twitter, etc A wide selection of journals (inclusive of 9 subjects, more than 200 journals)

Providing a 24-hour high-quality service

User-friendly online submission system

Fair and swift peer-review system

Efficient typesetting and proofreading procedure

Display of the result of downloads and visits, as well as the number of cited articles

Maximum dissemination of your research work

Submit your manuscript at: http://papersubmission.scirp.org/ 